\title{
Practical Physiological Monitoring Protocol for Heat Strain Control
}

\author{
R. B. Anderson, J. S. Johnson, S. R. Burastero, \\ O. E. Gilmore
}

July 1, 2003

U.S. Department of Energy

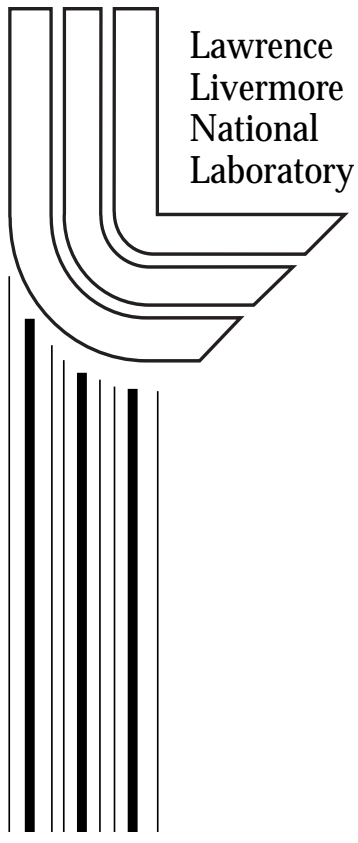


This document was prepared as an account of work sponsored by an agency of the United States Government. Neither the United States Government nor the University of California nor any of their employees, makes any warranty, express or implied, or assumes any legal liability or responsibility for the accuracy, completeness, or usefulness of any information, apparatus, product, or process disclosed, or represents that its use would not infringe privately owned rights. Reference herein to any specific commercial product, process, or service by trade name, trademark, manufacturer, or otherwise, does not necessarily constitute or imply its endorsement, recommendation, or favoring by the United States Government or the University of California. The views and opinions of authors expressed herein do not necessarily state or reflect those of the United States Government or the University of California, and shall not be used for advertising or product endorsement purposes.

This work was performed under the auspices of the U.S. Department of Energy by University of California, Lawrence Livermore National Laboratory under Contract W-7405-Eng-48. 


\section{PRACTICAL PHYSIOLOGICAL MONITORING PROTOCOL FOR HEAT STRAIN CONTROL}

\section{Scope:}

This protocol is indicated when employees are:

- Exposed to Heat Stress above the TLV; and,

- Performing low to moderate work rates with rare excursions to heavy rates; NOT for heavy and very heavy work rates or requiring peak outputs for extended periods; and,

- Determined to need physiological heat strain monitoring by the cognizant Industrial Hygienist.

\section{Requirements:}

- A work/rest regimen must be established at outset and adjusted as needed during operations (see Appendix A).

- On-going data collection and review.

- Rest times must be increased if indicated.

- Intended for normal, healthy adults. Seasonal medical screening is recommended.

- Training for affected employees regarding this protocol, hydration, self-limitation, lifestyle effects and signs, symptoms and treatment of heat related illnesses.

\section{Intent:}

This protocol is to aid industrial hygienists in assessing individual physiological response to employee heat exposures, and provides guidance to identify and reduce heat strain as needed.

Physiological monitoring is recommended when heat exposure exceeds the TLV by $\geq 2{ }^{\circ} \mathrm{C}$ and/or when evaporative cooling is limited or eliminated. Typically, this occurs when the use of personal protective equipment includes impermeable or water vapor restrictive outer garments. 
This protocol is used to identify when heat strain may be excessive. This is determined through measurements taken during each rest period. If decision criteria are exceeded, changes in work practices shall be implemented immediately to reduce employee heat strain and prevent heat related illnesses up to and including heat stroke, a life threatening condition.

This protocol may not be appropriate under all conditions. Sound Industrial Hygiene professional judgment is required. Because the measurements for this protocol occur during the rest phase of the work/rest regimen, the conditions affecting employee heat strain during the work phase must be carefully weighed. Work

\section{rate, effecting metabolic heat generation is the most}

important factor. However, it does have several advantages including: Ease of deployment, high employee acceptance, relatively non-invasive, encourages self-monitoring, enables onthe-spot work/rest regimen adjustments protecting worker health and documents the effectiveness of control methods.

\section{Medical Screening:}

Populations likely to be significantly exposed to heat stress/strain should be identified for pre-placement and annual medical screenings. This screening normally includes medical history and any respirator use, drug therapy and/or condition that may increase employee risk to heat strain or be physiologically unresponsive to those indices used in this protocol to indicate the level of heat strain present. Medical must notify supervisors of those individuals who may be more liable to suffer heat related disorders than normal healthy adults and make recommendations regarding work restrictions as necessary.

\section{Mechanism:}

The cognizant Industrial Hygienist must establish an initial, appropriate work/rest regimen. The recommended determinants for establishing the work/rest regimen are detailed in Appendix A. The work/rest regimen (\% time working vs. \% time resting) is

Thanks for your interest in this protocol. Feedback regarding successes, limitations and data resulting from it's use is greatly appreciated. Please contact Robert Anderson, CIH 
intended to allow the body to recover from increased heat loading due to metabolic and environmental factors incurred during work activities. The rest segment accomplishes this by ensuring a compensating rest period, free of protective clothing, in relatively cool surroundings. Two physiological indicators, Core Temperature and Seated Heart Rate, can be easily measured during rest periods and are considered good indicators of (heat strain) the body's internal heat load, response to and recovery from heat stress. These are detailed below:

Core Temperature: Oral (by mouth) Temp. is a standard means to gauge core temperature. Oral Temp. is expected to rise when work begins and then stabilize. If Oral Temp. continues to rise from one rest period to the next this indicates inadequate recovery time and is cause for concern. Compensatory action must be taken.

Seated Heart Rate: After 10 minutes, recovery from elevated heart rate due to muscular exertion from the work phase should be complete. Thus, after resting 10 minutes, measured increases in heart rate are likely due to the body trying remove excess heat. The body increases cooling capacity by circulating more blood to surface capillaries and raises the heart rate to accomplish this. The more heat the body retains, the higher the Seated Heart Rate will be to compensate. Seated Heart Rate is expected to increase when work begins and then stabilize. If the Seated Heart Rate continues to increase from one rest period to the next and does not resolve itself, this is a cause for concern and compensatory action must be taken.

\section{Data Collection - Adjustment:}

Each Oral Temp. and Seated Heart Rate data point is plotted on a graph for each individual worker (see Appendix C). The first points are pre-start or "baseline". Baseline measurements are taken when employees first don protective gear needed to conduct the work and are plotted on the $\mathrm{x}$-axis at Time $=$ " 0 ". Record the time of day (ie. 7:30 AM) at Time $=$ " 0 ". Consecutive

Thanks for your interest in this protocol. Feedback regarding successes, limitations and data resulting from it's use is greatly appreciated. Please contact Robert Anderson, CIH e-mail: anderson124@IInl.gov, phone: (925) 423-7861 page 5 of 17 
data points are plotted along the $\mathrm{x}$-axis as elapsed time since the baseline measurement.

Post-Entry data point: - This indicates that the employee just came out of work area.

Pre-Entry data point: - This indicates that the employee is going back into the work area after a scheduled rest period.

The graph readily shows the trend of the data. If these measured indicators continue to trend higher, then the work/rest regimen must be changed to allow the body sufficient time to reduce stored heat. This means more rest and less work.

\section{Decision Point - Oral Temperature:}

1. Look for trends. If the PRE-ENTRY Oral Temp. increases progressively over the course of the day, increase the rest time.

2. Consider a POST-ENTRY Oral Temp. reading of $37.5^{\circ} \mathrm{C}$, $\left(99.5^{\circ} \mathrm{F}\right)$ an OK reading after work has begun.

3. Consider a POST-ENTRY Oral Temp. reading of $38.0{ }^{\circ} \mathrm{C}$ $\left(100.4^{\circ} \mathrm{F}\right)$ the upper limit of acceptable. (Extend rest periods if POST-ENTRY Oral Temps. remain at this level or higher.)

4. Consider a POST-ENTRY Oral Temp. reading of $38.3^{\circ} \mathrm{C}$ $\left(101^{\circ} \mathrm{F}\right)$ the ceiling limit. Do not send the employee back to work. Extend the rest period until Oral Temperature has recovered to $37^{\circ} \mathrm{C}\left(98.6^{\circ} \mathrm{F}\right)$ or below. Continue to monitor the individual closely for signs of heat related disorders.

5. Consider a PRE-ENTRY Oral Temp. of $37{ }^{\circ} \mathrm{C}\left(98.6{ }^{\circ} \mathrm{F}\right)$ as OK. 
6. Consider a PRE-ENTRY Oral Temp. of $37.5^{\circ} \mathrm{C}\left(99.5^{\circ} \mathrm{F}\right)$ as too high. Allow the employee to rest until they have recovered.

\section{Decision Point - Seated Heart Rate:}

1. Look for trends. If the Seated Heart Rate trends up progressively over the course of the day, increase the rest time.

\section{Self-reporting:}

Pre-season Heat stress/strain training should occur. At a minimum, conduct a tailgate safety meeting to review heat strain disorders, symptoms and control methods.

Self-reporting heat related disorder symptoms should be encouraged and never dismissed. Always pay attention to this and allow personnel to self- regulate. In other words, if the person comes out of the work area and says " I'm just too hot and feel bad", or equivalent, that is OK. Allow them to rest and monitor them closely for symptoms of heat related illness.

If symptoms of employees who are reporting not feeling well do not resolve within 15 minutes, exclude them from further heat exposure and take the employee to medical for evaluation. While this is likely not an emergency at this point, do not delay in transporting the person to medical.

\section{Data Collection:}

\section{Oral Temperature: When to measure -}

Always get the employees POST ENTRY Oral Temp. immediately AFTER the employee exits the work area and BEFORE they drink water. Experience has shown that employees under heat stress/strain will not wait to drink liquids. Those taking these 
measurements must be ready when employees exit work areas to take breaks.

Measure the PRE-ENTRY Oral Temp. just before the employee reenters the work area. Take this measurement only if it has been at least 15 minutes since the last time they drank water.

Obviously, if the person is allowed only a 15-minute rest break, re-hydration takes precedence and a PRE-ENTRY Oral Temp.

measurement will not be taken. Do not block access or restrict water from employees during breaks.

\section{Remember:}

- Communicate: Review the protocol with the Supervisor and affected employees ahead of time. Determine to the degree possible when breaks will occur. Tell the employee you must take their Oral Temp. immediately upon exiting the work area. Also indicate that it will take just a few seconds (electronic thermometer) and that they must hold off on consuming water until this is done.

\section{Oral Temperature: How to Measure-}

The quickest easiest means of measuring Oral Temp is by using the SureTemp 679 Thermometer:

\section{NOTE: Always take 2 to 3 readings and record the highest reading.}

1. Pull the probe from the retainer.

2. Insert probe into disposable cover and press the down lower section of the probe until it clicks into place.

3. When you hear the beep and the display reads, "ORL", place probe/cover under employee's tongue and remain until it beeps (about 5 seconds). 
4. Pop off and discard the probe cover.

5. Record the Oral Temp. in ${ }^{\circ} \mathrm{C}$ on the chart provided for each employee.

An alternate method takes longer but requires no equipment nor batteries, the 3M - Tempa-Dot or Vicks Disposable Thermometers (single reading OK):

1. Use a new disposable thermometer for each measurement. Use a thermometer which reads in ${ }^{\circ} \mathrm{C}$ is preferred but a ${ }^{\circ} \mathrm{F}$ can also be used. Remember the conversion formula is: $\mathrm{C}=(5 / 9)(\mathrm{F}-32)$ or use the conversion chart (Appendix B.)

2. Take care to place the thermometer under the employee's tongue and well back in the mouth (without choking him/her). Leave it there for one (1) full minute. If the employee is willing and conditions appropriate, the thermometer can be retained by the employee while they remove protective clothing.

3. Read the thermometer immediately and record the Oral Temp. in ${ }^{\circ} \mathrm{C}$ on the chart for each employee.

\section{Seated Heart Rate: When to measure -}

After the employee has removed some outer garments and has been sitting for 10 minutes, take his/her Seated Heart Rate.

\section{Seated Heart Rate: How to measure -}

The Seated Heart Rate measurement is done via the radial pulse at the employee's wrist. Use your index and middle finger. Place these fingers flat over the inside surface of the wrist, along the thumb side. Count the number of beats for 15 seconds. Multiply this number by 4 . Plot the resulting number on the chart for each employee. 
Please direct questions or concerns about this protocol to the cognizant Industrial Hygienist or Rob Anderson, CIH @ 3-7861.

Thanks for your interest in this protocol. Feedback regarding successes, limitations and data resulting from it's use is greatly appreciated. Please contact Robert Anderson, CIH e-mail: anderson124@IInl.gov, phone: (925) 423-7861 


\section{Appendix A}

\section{Initial and Operational Work/Rest Regimen}

Establish an "initial" work/rest regimen using the WBGT method outlined in the ACGIH TLV booklet with expanded WBGT clothing adjustment additions. During operations, make necessary changes in the work/rest regimen to reflect changes in WBGT readings (environmental factors), clothing ensemble and work rate. The expanded list of WBGT clothing adjustment additions in the table below have been have been reproduced from available peer reviewed literature:

1. Determine the environmental WBGT reading for the work location.

2. Determine the work rate: light, medium or heavy*. * Heavy work rates limited to short duration but must be accounted for.

3. Using Table 1., determine the appropriate clothing factor adjustment and add that to the WBGT number.

4. Locate the resulting value $\leq$ to this number on Table 2 . and determine the appropriate work/rest regimen.

Note: Under circumstances where Work is $100 \%$, a Standard break each 2 hours is expected. 
Table 1.

\section{Recommended WBGT Clothing Adjustment Factors for various Clothing Ensembles}

\section{Clothing Ensemble Description}

Std. 4 oz L-Sleeve cotton shirt and 8 oz cotton pants, equals reference ensemble for setting Clothing Adjustment Additions. +

Cloth coveralls (CC) std. anti-contamination coveralls with hood and hand and foot coverings, cotton or cotton poly blend wts. 8-9 oz. +

Cloth coveralls over scrub suit: or CC plus set of $20 z$ underalls (surgical scrub suit. $\dagger$

Double cloth coveralls or CC with second set of CC only. $\dagger$

SMS polypropylene coveralls; limited use coveralls with hood (particle barrier only) made of melt blown polypropylene. $\dagger$

DuPont, Kappler Tyvek $® 1424$ without hood and gloves *

DuPont, Kappler NexGen $®$ without hood and gloves $*$

DuPont, Kappler TyChem $®$ without hood and gloves $*$

MB polyethylene coveralls, limited use with hood, (particle barrier only) made from a melt blown polyproplylene (Tyvek 1422A) +

Polyester coveralls; lightweight polyester ( $98 \%$ Nylon $30 z$. with a hood of the same material (ProTech2000). †

Polyester coveralls; lightweight polyester w/ a hood of same material worn over a surgical scrub suit. $\dagger$ Water Barrier, vapor permeable coveralls; limited use, coveralls with hood made from a tri-laminate fabric of with a tetraflouoroethylene micro-porous film. +

Water Barrier, vapor permeable coveralls; limited use, coveralls with hood made from a tri-laminate fabric of micro-porous film. +
Recommended WBGT Clothing Adjustment Additions $\left({ }^{\circ} \mathrm{C}\right)$ 0

\section{5}

4.5

5.0

$-1.0$

1.0

2.0

10.0

2.0

\section{0}

3.0

6.0

2.5

Thanks for your interest in this protocol. Feedback regarding successes, limitations and data resulting from it's use is greatly appreciated. Please contact Robert Anderson, CIH e-mail: anderson124@IInl.gov, phone: (925) 423-7861 


\begin{tabular}{|c|c|}
\hline Clothing Ensemble Description (continued) & $\begin{array}{l}\text { Recommended } \\
\text { WBGT Clothing } \\
\text { Adjustment } \\
\left.\text { Additions ( }{ }^{\circ} \mathrm{C}\right)\end{array}$ \\
\hline $\begin{array}{l}\text { Vapor-Barrier coveralls and hood mad of light weight } \\
\text { fabrics designed for limited use worn over cloth } \\
\text { coveralls; typical fabrics may be a polyethylene } \\
\text { coated spun bonded polyethylene or a polyvinyl } \\
\text { chloride. }+\end{array}$ & 8.5 \\
\hline $\begin{array}{l}\text { Encapsulating suit or turn-out gear; total } \\
\text { encapsulating suits (e.g. Level A); reusable whole } \\
\text { body chemical protective suits; firefighter turn-out } \\
\text { gear. }+\end{array}$ & 11 \\
\hline $\begin{array}{l}\text { Flame-retardant shirt and pants, long-sleeve Zirpo } \AA \\
\text { wool shirt and pants made from FR8 } \AA \text { treated } \\
\text { cotton fabric. }+\end{array}$ & 0.5 \\
\hline $\begin{array}{l}\text { Flame-retardant shirt and pants, long-sleeve shirt } \\
\text { and pants made pants made from FR9 } \AA \text { treated } \\
\text { cotton fabric. }+\end{array}$ & 1.0 \\
\hline $\begin{array}{l}\text { Flame-retardant shirt and pants, with single layer } \\
\text { jacket long-sleeve shirt and pants and jacket made } \\
\text { from FR9 } \AA \text { treated cotton fabric. }+\end{array}$ & 2.0 \\
\hline $\begin{array}{l}\text { Flame-retardant shirt and pants, with double-layer } \\
\text { jacket; long-sleeve shirt and pants and double-layer } \\
\text { jacket made from FR } ₫ \text { treated cotton fabric. } \dagger\end{array}$ & 3.0 \\
\hline
\end{tabular}

+ Bernard, T.E,(1999) Heat Stress and Protective Clothing: An Emerging Approach from the United States; Annals of merican Occupational Hygiene., Volume 43, 321-327.

* Bernard, T., et al, (2003) AIHCE, Dallas, TX; WBGT Offsets for Four Clothing Ensembles at Moderate Metabolic Rate.

Thanks for your interest in this protocol. Feedback regarding successes, limitations and data resulting from it's use is greatly appreciated. Please contact Robert Anderson, CIH e-mail: anderson124@IInl.gov, phone: (925) 423-7861 
Table 2.

\section{Work/Rest Regimen Determinants for Various Work Rates For Un-acclimatized Workers $\left({ }^{\circ} \mathrm{C}\right)$}

\begin{tabular}{|c|c|c|c|}
\hline $\begin{array}{l}\text { Minutes } \\
\text { Work / } \\
\text { Minutes } \\
\text { Rest } \\
\text { Per Hour }\end{array}$ & $\begin{array}{l}\text { Low Work } \\
\text { Rate: Ex. } \\
\text { Sitting or } \\
\text { standing } \\
\text { controlling } \\
\text { machines }\end{array}$ & $\begin{array}{l}\text { Medium Work } \\
\text { Rate: } \\
\text { Ex. Walking } \\
\text { around with } \\
\text { moderate } \\
\text { lifting and } \\
\text { pushing }\end{array}$ & $\begin{array}{l}\text { High Work } \\
\text { Rate: Ex. } \\
\text { Pick and } \\
\text { shovel } \\
\text { work }\end{array}$ \\
\hline $\begin{array}{l}60 \text { min. / } \\
0 \text { min. }\end{array}$ & 27.5 & 25 & 22.5 \\
\hline $\begin{array}{l}45 \mathrm{~min} . / \\
15 \mathrm{~min} .\end{array}$ & 29 & 26.5 & 24.5 \\
\hline $\begin{array}{l}30 \mathrm{~min} . / \\
30 \mathrm{~min} .\end{array}$ & 30 & 28 & 26.5 \\
\hline $\begin{array}{l}15 \text { min./ } \\
45 \text { min. }\end{array}$ & 31 & 29 & 28 \\
\hline
\end{tabular}

Source: ACGIH TLV Booklet, 2002, Heat Stress \& Strain 


\section{Appendix B. Temperature Conversion Table}

\begin{tabular}{|c|c|}
\hline Deg. F & Deg. C \\
\hline 97 & 36.1 \\
\hline 97.2 & 36.2 \\
\hline 97.4 & 36.3 \\
\hline 97.6 & 36.4 \\
\hline 97.8 & 36.6 \\
\hline 98 & 36.7 \\
\hline 98.2 & 36.8 \\
\hline 98.4 & 36.9 \\
\hline 98.6 & 37.0 \\
\hline 98.8 & 37.1 \\
\hline 99 & 37.2 \\
\hline 99.2 & 37.3 \\
\hline 99.4 & 37.4 \\
\hline 99.6 & 37.6 \\
\hline 99.8 & 37.7 \\
\hline 100 & 37.8 \\
\hline 100.2 & 37.9 \\
\hline 100.4 & 38.0 \\
\hline 100.6 & 38.1 \\
\hline 100.8 & 38.2 \\
\hline 101 & 38.3 \\
\hline 101.2 & 38.4 \\
\hline 101.4 & 38.6 \\
\hline 101.6 & 38.7 \\
\hline 101.8 & 38.8 \\
\hline
\end{tabular}

Thanks for your interest in this protocol. Feedback regarding successes, limitations and data resulting from it's use is greatly appreciated. Please contact Robert Anderson, CIH 


\title{
Appendix C. Field Use - Data Tracking Sheet
}

\author{
This page intentionally blank.
}

Thanks for your interest in this protocol. Feedback regarding successes, limitations and data resulting from it's use is greatly appreciated. Please contact Robert Anderson, CIH e-mail: anderson124@IInl.gov, phone: (925) 423-7861 

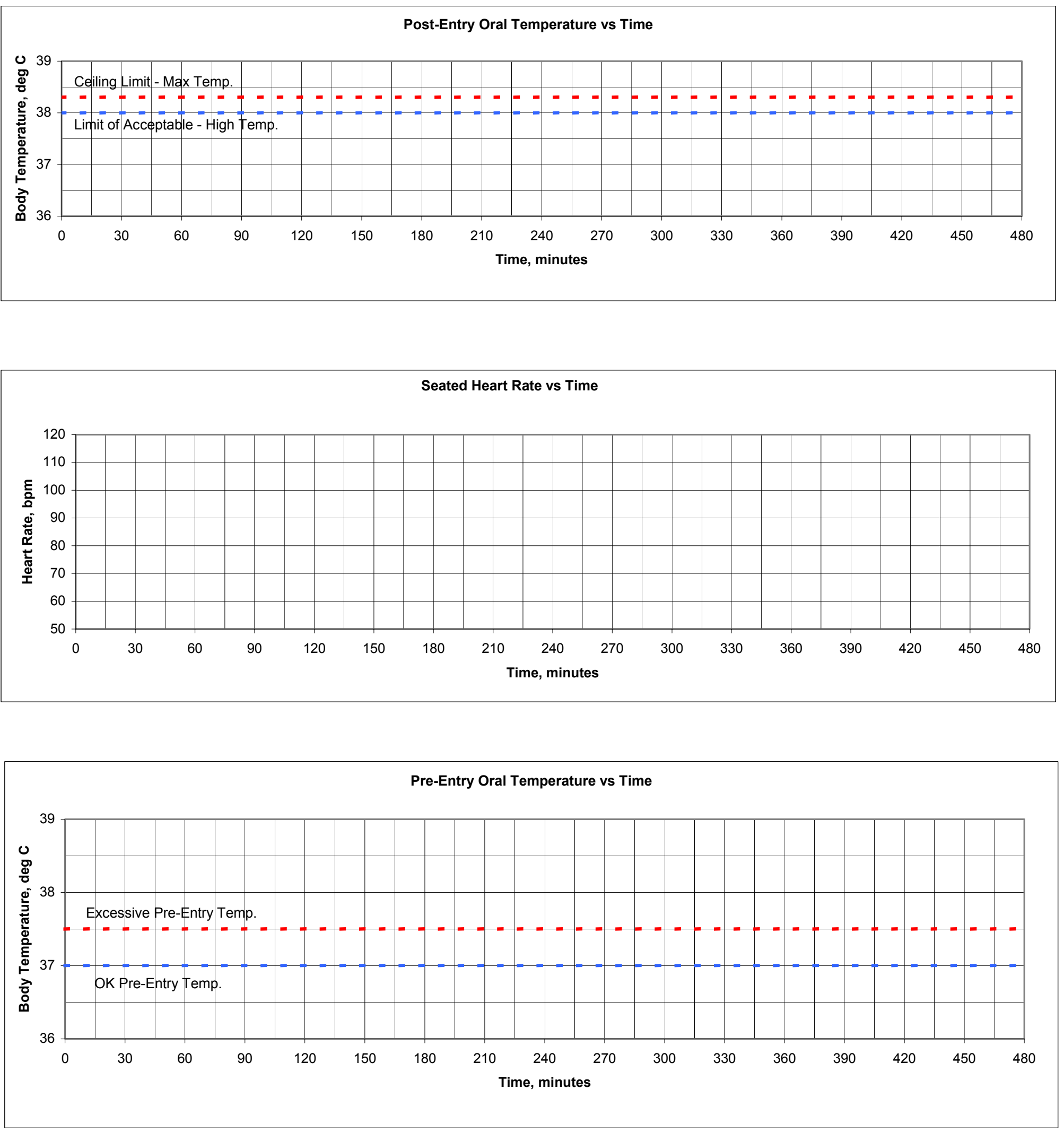

Thanks for your interest in this protocol. Feedback regarding successes, limitations and data resulting from it's use is greatly appreciated. Please contact Robert Anderson, CIH e-mail: anderson124@IInl.gov, phone: (925) 423-7861 